\title{
A Protocol for Indefinite Determiners in Italian and Italo-Romance
}

\author{
Giuliana Giusti
}

This paper is dedicated to Carme Picallo, a mother of modern Romance linguistics, and a pioneer in the study of noun phrases, who passed away on June 7, 2019. We shall miss her.

\section{Introduction}

As observed by Brasoveanu and Farkas (2016), indefiniteness is such a broad topic in semantics and pragmatics that a simple definition cannot be reached in a few lines. One way to approach the definitory problem is to refer to its positive counterpart; that is, definiteness. In this perspective, if a definite nominal refers to an individual already mentioned in the discourse, an indefinite nominal may introduce a new individual in the discourse, or it may not refer at all. There are different types of indefiniteness, combining for different values of specificity and presupposition of existence. ${ }^{1}$ For example, while in (1a-b) the objects wine or violets are non-specific (weak indefinites, according to Milsark 1977; Diesing 1992), in (1c) the subject students can either refer to existing individuals that the speaker has in mind, or to non-specific individuals whose existence the speaker is not committed to:
(1) a. Iwill drink wine.
b. I will pick violets.
c. Students will arrive.

1 Cf. Ihsane, this volume, on specificity and complements with a "partitive article" in French. 
All the indefinites in (1) are called "uncontroversial indefinites" by Brasoveanu and Farkas (2016) to distinguish them on the one hand from quantificational indefinites (as some children, some of the children, also called strong indefinites in the literature; see McNally 2020 for an overview) and on the other hand from marked indefinites, such as those introduced by the complex determiner "a certain" (see Schwarz 2011, for an overview).

In this paper, I focus on uncontroversial indefinites in Italian and ItaloRomance varieties. The interest of the enterprise is due to the fact that in addition to bare nominals, these languages present a variety of determiners, including the definite article, the bare preposition di, the so-called "partitive article" and possibly the use of certain with singular mass and plural nouns, as in (2), which may have the same non-quantificational interpretation as (1a-b) above:
a. Berrò
vino / ilvino / divino / delvino

[I] will.drink wine / the wine / of wine / PA.M.SG wine

/ certo vino

/ certain wine

'I'll drink wine.'

b. Raccoglierò violette / le violette / diviolette / delle violette [I] will.pick violets / the violets / of violets / PA.F.PL violets / certe violette / certain violets 'I'll pick violets.'

According to Cardinaletti and Giusti $(2018,2020)$ these constructions distribute in different ways across dialects and regional varieties of informal Italian, with different nuances of indefiniteness. The goal of this paper is to provide a tool to detect variation and optionality in the use of these elements and define the specialization of meaning associated to them. This will be carried out in what I call a "protocol methodology", a metatheoretical approach, informed of the advances of current linguistic research, which pins down the properties and features relevant for the discussion, abstracting away from framework specific technicalities that may hinder the communication among linguists of different persuasions and with scholars in non-linguistic disciplines, such as education, language policy, language accessibility and clinical treatments.

The paper is structured as follows. Section 2 provides an overview of the different forms to express indefiniteness in Italo-Romance set in a pan-Romance

2 The term "partitive article" is used here in an atheoretical sense. Strictly speaking, in our work 
perspective. Section 3 assesses the diagnostics for the expression of indefiniteness in Italo-Romance according to seven features: (i) grammatical function; (ii) scope; (iii) noun classes; (iv) verbal aspect; (v) clause types; (vi) specializations of meaning; (vii) lexical collocation. Section 4 presents the aims and goals of the protocol approach and how the diagnostics discussed in Section 3 can be organized in protocols providing an adequate tool to capture the fine-grained dimensions of variation and optionality among indefinites. Section 5 draws the conclusions, highlighting how the protocol methodology can encompass crosstheoretical misunderstandings.

\section{The Empirical Domain}

\section{1}

\section{The Pan-Romance Perspective}

In Germanic languages, bare nominals are found in object and subject position, as in English (3)-(4) where the indefinite determiner some, more precisely a weak variant of it, often referred to in the literature as s'm (see Milsark 1977; McNally 2020), is possible but not obligatory in either position:

(3) a. I drank (some) wine.

b. I picked (some) violets.

(4) a. (Some) wine is on the table.

b. (Some) violets are blooming in my garden.

Romance languages are different from Germanic languages (see Strobel and Glaser, this volume, for a discussion of partitive markers in Germanic). Delfitto and Schroten (1991) observe that while Dutch (like English) has bare nominals in both subject (5a) and object positions (6a), Spanish only has them in object position (6b) vs. (5b), while French disallows them in both positions (5c) and (6c):
(5) a. Studenten hebben het gebouw bezet.
Dutch
b. * Estudiantes han ocupado el edificio. Spanish
c. * Étudiants ont occupé l'édifice.
French 'Students have occupied the building.'

\footnotetext{
it is a determiner, not an article, since the di component is in SpecDP (cf. Section 5). This is represented in the text with the annotation di+art and in the examples with the gloss PA for "partitive article".
} 
(6)
a. Ik heb
studenten in het gebouw gezien.
Dutch
b. Yo he visto estudiantes en el edificio. Spanish
c. * $J$ ' ai vu étudiants dans l'édifice.
French

'I have seen students in the building.'

Where bare nominals are not allowed, overt determiners must appear. Spanish and French present two different types of overt indefinite determiners: the plural form of the singular indefinite "one" and the so-called "partitive article" formed by a grammaticalized preposition $d e$ 'of' inflected with a definite article bleached of its definite meaning (Carlier 2007; Ihsane 2008; Carlier and Lamiroy 2014). ${ }^{3}$ Note that in object position, these determiners are in competition with bare nominals in Spanish but mandatory in French, which is the only Romance language that does not allow for bare nominals:
a. *(Unos) estudiantes han ocupado el edificio.
Spanish
b. *(Des) étudiants
ont occupé l'édifice.
French
'Students have occupied the building.'
a. Yo he visto (unos) estudiantes en el edificio.
Spanish
b. J' ai vu *(des)étudiants dansl'édifice.
French
'I have seen students in the building.'

The subject/object asymmetry found in Spanish is widespread across Romance (Stark 2008a, 2008b, 2016; Carlier and Lamiroy 2018).

Variation is also found in the forms of the determiners: Portuguese, Spanish, Catalan and Romanian display no determiner with mass nouns, as illustrated in ( $9 \mathrm{a}-\mathrm{c})$ and ( $9 \mathrm{f})$, and the plural form of the indefinite article "one" with plural count nouns, (10a-c) and (1of) (see Dobrovie-Sorin, this volume, for some discussion of Romanian). French and Italian display the "partitive article" with both mass nouns and plural count nouns. In French, (9d) and (1od), the "partitive article" is the only available form, while in Italian it covaries with bare nominals as illustrated in (9e) and (10e). Finally, in Romanian (9f) and (1of), we find the uninflected indefinite determiner nişte for both mass and plural count nouns, on a par with bare nominals and the plural "one" for count nouns:

3 Note that there are semantic differences between Spanish unos, French $d u / d e s$ and Romanian nişte and unele that cannot be discussed here for space reasons. Note also that when overt determiners compete with bare nouns, they are expected to have specialized meaning (see Section 3.6). 


\begin{tabular}{|c|c|c|c|}
\hline a. $B e b i$ & & vinho. & Portuguese \\
\hline b. Bebi & & vino. & Spanish \\
\hline c. Vaig beure & & $v i$. & Catalan \\
\hline d. J'ai bu & $d u$ & vin. & French \\
\hline e. Ho bevuto & $(\mathrm{del} / \mathrm{il})$ & vino. & Italian \\
\hline f. $A m b a \breve{u t}$ & (nişte) & vin. & Romanian \\
\hline $\begin{array}{l}\text { drink.1SG.PST } \\
\text { 'I drank wine.' }\end{array}$ & (DET) & wine & \\
\hline
\end{tabular}

\begin{tabular}{llll} 
(10) a. Apanhei & (umas) & violetas. & Portuguese \\
b. Cogi & (unas) & violetas. & Spanish \\
c. Vaig collir & (unes) & violetes. & Catalan \\
d. J'ai cueilli & des & violettes. & French \\
e. Ho raccolto & (delle/le) & violette. & Italian \\
f. Am cules & (nişte/ unele) & violete. & Romanian \\
\multicolumn{2}{c}{ pick.1SG.PST (DET) } & violets &
\end{tabular}

These facts are well known in the literature on individual languages. What is less known is the fact that the definite article can (marginally) appear in nominals with indefinite interpretation, in all Romance languages except the most lateral ones, namely Portuguese and Romanian, as represented in (11b-e) with a modified mass noun "bottled water" in a generic sentence expressing a habit:

\begin{tabular}{llll} 
(11) a. Bebo & água & de garrafa. & Portuguese \\
b. Bebo & $($ el) agua & embotellada. & Spanish \\
c. Bec & $\left(l^{\prime}\right)$ aigua & en ampolla. & Catalan \\
d. Je bois & $($ de) l'eau & en bouteille. & French \\
e. Bevo & $\left(l^{\prime}\right.$ )acqua & in bottiglia. & Italian \\
f. Beau & apă & din sticlă. & Romanian \\
& drink.1SG.PRS (DET) water in bottle / bottled & \\
\multicolumn{2}{c}{ 'I drink bottled water.' } &
\end{tabular}

Since Romance languages express reference to kind with the definite article, it could at first sight be argued that the direct object in (11) refers to kind when it is introduced by the definite article. But this would be wrong for two reasons. First, the definite article is much more restricted in similar contexts with an unmodified plural count noun, as in (12), where only Italian and Catalan still allow for the definite article: 


$\begin{array}{lll}\text { (12) a. Não como } & \text { batata(s). } & \text { Portuguese } \\ \text { b. No como } & \text { patatas. } & \text { Spanish } \\ \text { c. No menjo } & \text { (les) patates. } & \text { Catalan } \\ \text { d. Je ne mange pas } & \text { de/??les patates. } & \text { French } \\ \text { e. Non mangio } & \text { (le) patate. } & \text { Italian } \\ \text { f. } N u \text { mănânc } & \text { cartofi. } & \text { Romanian } \\ & \text { NEG eat.1SG.PRS (DET) potato.sG/PL } & \\ & \end{array}$

Second, this distinction is not found with the attitude predicates in (13)-(14), which can select a kind-referring object (see Laca 199o; Krifka et al 1995). In this case, all Romance languages require the definite article, except Portuguese which, however, does not rule it out: ${ }^{4}$

\begin{tabular}{llll} 
(13) a. Evito & (a) água & de garrafa. & Portuguese \\
b. Evito & el agua & embotellada. & Spanish \\
c. Evito & l'aigua & en ampulla. & Catalan \\
d. J'évite & l'eau & en bouteille. & French \\
e. Evito & l'acqua & in bottiglia. & Italian \\
\multicolumn{2}{c}{ avoid.1SG.PRS (DET) water in bottle / bottled } & \\
f. Evit & apa & imbuteliată. & Romanian \\
avoid.1SG.P Rs water.the & bottled & \\
'I avoid bottled water.' & &
\end{tabular}

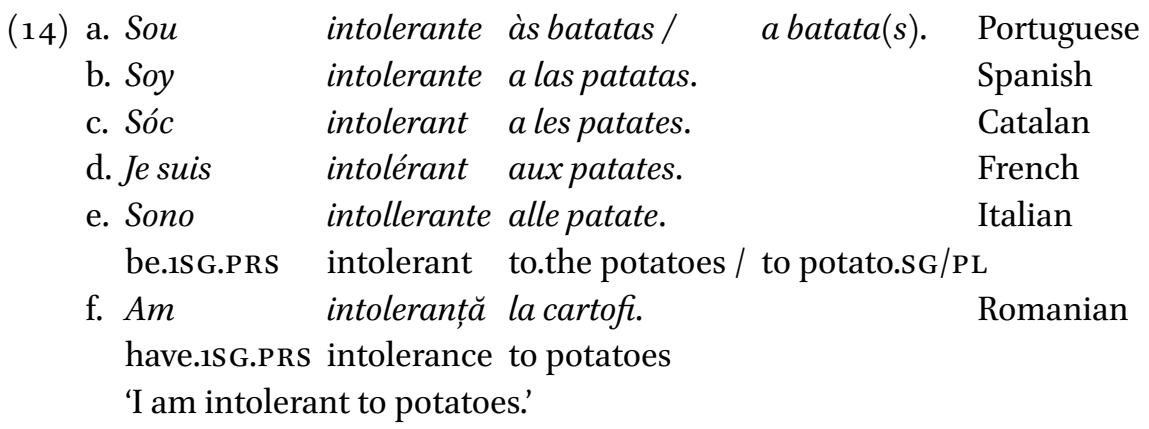

The contexts in (9)-(12) present different grammatical features that interact with indefiniteness. In (9)-(10) the mass noun "wine" and the count plural "vio-

4 Note that the definite article must be missing in Romanian if a definite or kind referring expression is unmodified and embedded in a PP, but this holds of both kind referring and definite nominals. 
lets" are the object of an episodic predicate in the past tense. In this context all languages, except French, have bare nouns. With mass nouns only Italian and Romanian display an overt alternative indefinite determiner. With plural count nouns all languages have an alternative. In (9)-(10) the definite article is an alternative only in Italian. In (11) the mass noun "water" is modified by a preposition or an adjective. ${ }^{5}$ This is probably what makes the definite article also possible in Spanish, Catalan and French, as well as in Italian. In (12), where the indefinite object is unmodified and under the scope of negation, the definite article is impossible in all the Romance languages, except Catalan where it is only marginal and in Italian where it is fully acceptable.

This short overview in the pan-Romance perspective suggests that French is the language that mostly requires overt determiners, while Italian is the language with the largest variation of forms, including the definite article generalized in the four indefinite contexts in (9)-(12). ${ }^{6}$ When more than one form is possible, the question arises about the conditions that govern the competition among the forms. We expect to find variation in the semantic interpretation and syntactic distribution across speakers, as well as across dialects and regional varieties of Italian.

\subsection{Variation in Italo-Romance Dialects}

Cardinaletti and Giusti (2018) analyze three AIs maps (Jaberg and Jud 19281949; Tisato 2009), displaying indefinite nominal expressions, that is, map 637 '[to look for] violets', map 1037 '[if there was] water', and map 1343 '[go to the cellar] to take wine', finding large variation and optionality among four possibilities, illustrated with Italian in (15)-(18).

In (15) we see a bare nominal, with no overt determiner:

(15) a. Ho bevuto vino.
have.1sG.PRS drunk wine

b. Ho raccolto violette.

have.1SG.PRS picked violets

5 The prenominal / postnominal position of adjectives in indefinite nominals also contributes to different specificity interpretations, see Picallo $(1994,2012)$. Given the preliminary nature of this study, the complexity of the interaction with adjectives is only hinted upon and will be left for future research.

6 Kupisch and Koops (2007) note that the Italian definite article occurs in indefinite contexts, such as portare la giacca 'wear a jacket' or avere la macchina 'have a car' (also see Korzen 1996) in which French would display an indefinite article, like English. They analyze this contrast 
The same indefinite meaning can be conveyed by a definite article, as in (16), which is in principle ambiguous between definite and indefinite interpretation. For example, (16a) is appropriate in the context "In my whole life, I have drunk wine many times", in which the predicate wine-drinking does not refer to any definite (quantity of) wine; and (16b) can easily be interpreted as referring to the activity of violet-picking, with no reference to previously mentioned violets:
(16) a. Ho
bevuto ilvino.
have.1SG.PRS drunk the wine
b. $H o$
raccolto le violette.
have.1SG.PRS picked the violets

In (17), we find the so-called "partitive article", formed with di and a definite article, typical of Gallo-Romance varieties.
(17) a. Ho
bevuto del vino.
have.1SG.PRS drunk PA.M.SG wine
b. Ho
raccolto delle violette.
have.1SG.PRS picked PA.F.PL violets

In (18), also parallel to Gallo-Romance varieties outside Italy, we find the bare preposition di. Note that while (15)-(17) are attested in Standard Italian, (18) should be taken as a meta-representation of dialectal data. In fact, only Piedmontese varieties have bare di (Berruto 1974; Cerruti and Regis 2020, and the references therein):
(18) a. Ho
bevuto divino.
have.1SG.PRS drunk of wine
b. Ho raccolto diviolette. have.1SG.PRS picked of violets

proposing that the grammaticalization of the definite article is one step further in Italian than in French (see Schurr, this volume, for further discussion of grammaticalization facts in Romance). We observe here extensively that this is also the case for mass and count nouns. 
The four ways to express indefiniteness, illustrated in (15)-(18), correspond to plural and mass indefiniteness, confirming the general tendency displayed in Romance and Germanic for the two types of bare nouns to behave alike, and unlike singular count nouns. In Italian and all Italo-Romance varieties, singular count nouns display an obligatory indefinite article (19a), with no plural (19b) or mass (19c) counterpart. The only possible interpretation of (19c) is of a (countable) type of wine; for this reason, it is not given as ungrammatical, but it is indicated as \#, which stands for unacceptable in the intended meaning (mass indefinite):

(19) a. Ho raccolto una violetta.

have.1SG.PRS picked a/one violet

b. ${ }^{*} \mathrm{Ho} \quad$ raccolto une violette.

have.1SG.PRS picked one.F.PL violets

c. \#Ho bevuto un vino.

have.1SG.PRs drunk a wine

Following Cardinaletti and Giusti's (2018) terminology, I will call the missing article in (15) ZERO, the definite article with indefinite interpretation in (16) ART, the "partitive article" $d i+\operatorname{art}$ in (17), and the indefinite determiner homophonous to the preposition di in (18) bare di.

Cardinaletti and Giusti's (2018) detailed analysis of the AIs maps 637, 1037, and 1343 reports the following areal distribution of indefinite determiners. The extreme northern and southern varieties favour ZE RO; a large part of Italy displays a strong preference for ART; few varieties of the North-West favour bare $d i$; a compact area starting from Liguria and northern Tuscany, including the whole Emilia and Romagna and reaching the northern Marches favours di+art. This distribution can be captured by two independent isoglosses: a NorthSouth isogloss favouring ART, surrounded by an area (northern Piedmont, northern Lombardy, northern Veneto, southern Apulia, southern Calabria and the whole of Sicily and Sardinia) favouring zERO; a West-East isogloss (from central Piedmont to the central-northern Adriatic regions ending in Ancona) favouring $d i$, surrounded by an area where $d i$ is not used. Where the two isoglosses overlap (in southern Lombardy, southern Veneto, the whole of Emilia Romagna and the northern Marches), $d i+$ art is the favourite form. According to Cardinaletti and Giusti (2018), this is evidence for the independent categorial status of di and ART, the former being a determiner in SpecDP and the latter being the overt realization of functional nominal features (number and gen- 
der, see Picallo 1991) in D. I will not dwell on the formal analysis of the four forms, referring the interested reader to that work.

Interestingly, very few varieties display just one form. Most varieties have more than one. When several forms are available, it appears that one has core indefinite meaning, whereas the others specialise. With "core indefinite meaning" Cardinaletti and Giusti (2018) intend the most basic notion of indefinites, namely those nominals that do not presuppose the existence of the referent or any other special meaning. This is the case of the AIs map 1037 'if there was water', where the indefinite nominal is in the scope of a hypothetical operator. In the AIs map 637 'to pick violets' the particular verb-object collocation enforces the special meaning of "small quantity", because violets are generally gathered in small bunches. The AIs map 1343 'go to the cellar to take wine' enforces a "salient" meaning, again due to the verb-object collocation, because a cellar is generally the place where wine is stored. This will be considered in more detail in Section 3.6.

The three AIs maps all display weak indefinites with narrow scope in postverbal positions, that is, the referent of the indefinite object is not (necessarily) presupposed to exist (see Brasoveanu and Farkas 2016; McNally 2020). Furthermore, we know from the literature that there are other forms to express indefiniteness in Italo-Romance dialects competing with the four indefinite determiners found with mass and plural count nouns, illustrated in (15)-(18). They appear sporadically on the three AIs maps studied by Cardinaletti and Giusti (2018). Dialects have many ways to express small quantity, mostly with quantity nouns selecting the preposition di 'of' and no article. This ranges from general 'a little', for example, un po' di vino 'a bit of wine' (see AIs map 1343, 523 Firenze), un poko de viole mamole 'a bit of violets' (see AIs map 637, Crespadoro (VI)), to measure nouns selecting a type of substance, for example, un sorso d'acqua 'a gulp of water' (see AIs map 1037, left column) or istu pezzu de legname 'this piece of wood', (see AIs map 538, 624 Rieti); or collective nouns, for example, ne mattso da viola 'a bunch of violets', (see AIs map 637, 707 Lucera $(\mathrm{FG})$ ) or the grammaticalized cardinal 'two', for example, du viole bambele 'two violets' (see AIs map 637, 59o Porto Santo Stefano (GR)).

Another form, reported in the dialectal literature, but not occurring in any relevant AIs map is certo 'certain'. It appears in some southern Italian dialects, as a genuine indefinite determiner. We find an example with a mass noun fieno 'hay' in (20a) and a plural noun kundi 'stories' in (2ob):
(20) a. S'era
corcato mmiezo a ccerto fieno.
Neaples
be.3SG.PST lying on to certain hay
'He was lying on hay.' (Rohlfs 1968, 118) 


\section{b. certi kundi}

Avezzano (L'aquila)

certain stories

'some stories' (Giammarco 1979, 141)

Certo with determiner function is present in all Italo-Romance varieties, as the mass singular / count plural counterpart of the marked indefinite determiner un certo "a certain", which is parallel to its English counterpart (cf. Farkas 2002; Schwarz 2011).

In (21) certo occurs with a mass noun (21a) and a plural count noun (21b), but not with a singular count noun (21c), on a par with di and ART above. Furthermore, with plural count nouns, it ambiguously specifies either the referent or the type of referent, as indicated by the two translations in (21b); with mass nouns it only refers to the type, (21a); with singular count nouns it only refers to a specific referent $(21 \mathrm{c})$ :

(21) a. Mangio solo certa pasta.

eat.1SG.PRS only certain pasta

'I only eat a certain type of pasta.'

b. Conosco certe persone.

know.1SG.PRs certain persons

'I know some people of a specific type.' / 'I know some specific people'

c. Conosco *(una) certa persona.

know.ISG.PRS a certain person

'I know a specific person.'

Such a profusion of forms in the local dialects at the first half of last century witnessed by AIS and the dialectal literature, raises questions regarding both the development of these forms in the modern dialects in contact with Standard Italian and the presence and status of these forms in regional (informal) Italian in contact with the local dialects. This paper is a first step of a large research project aiming to explore variation and optionality in the expression of indefiniteness in modern local dialects as well as in modern informal Italian. 


\section{$3 \quad$ Diagnostics for Indefiniteness}

This section aims at highlighting the different semantic and pragmatic contexts where different indefinite determiners can appear. In this view, it is important to disambiguate the definite article with indefinite interpretation (ART), from the better studied reference to kind and definite interpretations of the definite article.

In principle, l'acqua 'the water' in (22), or le zanzare 'the mosquitos' in (23) are three times ambiguous and can only be disambiguated by the context: in $(22 a)$ and $(23 a)$ they are kind-referring, in $(22 b)$ and $(23 b)$ they are indefinite, and in $(22 \mathrm{c})$ and $(23 \mathrm{c})$ they are definite:

(22) a. L'acqua abbonda in questa regione.

the water abounds in this region

'Water abounds in this region.'

b. Ho versato l'acqua nel bicchiere.

have.1SG.PRES poured the water in.the glass

'I poured water in my glass.'

c. L'acqua che ho preso dal frigorifero era troppo fredda.

'The water that I took from the fridge was too cold.'

(23) a. Le zanzare sono molto diffuse in questa regione.

the mosquitos are very widespread in this region.

'Mosquitos are very wide-spread in this region.'

b. In questa stanza (non) ci sono le zanzare.

in this room (NEG) there are the mosquitos

'In this room, there are (no) mosquitoes.'

c. Lezanzare che mi hanno punto eranofastidiose.

the mosquitoes that =1SG.ACC have bit were annoying

'The mosquitoes that bit me were annoying.'

\subsection{Grammatical Function}

The predicates in (22a) and (23a) select a kind-referring subject and are incompatible with an object-referring nominal. A subject with a ZERO determiner, as in (24a) and (25a), is excluded for the independent reason, seen for Spanish in $(5 \mathrm{~b})$ and $(7 \mathrm{a})$ above, that in Romance languages, bare nouns in subject position 
are ungrammatical (cf. Dobrovie-Sorin, this volume; and Martin, Carvalho and Alexiadou, this volume, for Brazilian Portuguese examples where the subject is reinterpreted as an event type). But the fact that (24b) and (25b) with an overt "partitive article" are also ungrammatical shows that the definite article in (22a) and (23a) does not express indefiniteness but reference to kind. In (7) above, indefinite subjects in Spanish and French must display an overt determiner (unos in Spanish and the "partitive article" in French). This is also the case in Italian, which displays $d i+$ art, as shown by the episodic sentences in (26):

(24) a. *Acqua abbonda in questa regione. water abounds in this region

b. *Dell'acqua abbonda in questa regione. PA.F.SG water abounds in this region 'Water abounds in this region.'

(25) a. *Zanzare sono molto diffuse in questa regione. mosquitos are very widespread in this region.

b. *Delle zanzare sono molto diffuse in questa regione. PA.F.PL mosquitos are very widespread in this region. 'Mosquitoes are wide-spread in this region.'

(26) a. Dell'acqua sta scorrendo nella canaletta. PA.F.SG water is running in.the pipe 'Water is running in the pipe.'

b. Delle zanzare stanno ronzando nella mia camera. PA.F.PL mosquitos are buzzing in.the my room 'Mosquitoes are buzzing in my room.'

Bare nominals can occur in subject position provided they are modified by postnominal or prenominal adjectives (or prepositional adjuncts). The contrasts in (27)-(28) confirm that ZERO can never appear in the subject of predicates selecting for kind, while it can appear in indefinite subjects, obeying some restrictions:

(27) a. *Acqua fresca e pulita abbonda in questa regione. water fresh and clean abounds in this region 'Fresh and clean water abounds in this region.' 
b. Acqua fresca e pulita scorre giù dalla montagna. water fresh and clean runs down from the mountain 'Fresh and clear water runs down from the mountain.'

(28) a. *Pericolosissime zanzare tigre sono diffuse in questa regione. 'Very dangerous tiger mosquitoes are wide-spread in this region.'

b. Pericolosissime zanzare tigre ronzavano nella mia stanza. Very dangerous mosquitoes tiger were-buzzing in.the my room 'Very dangerous tiger mosquitoes were buzzing in my bedroom.'

In episodic sentences with positive or negative polarity (29)-(30), the object can be indefinite, as shown by the fact that it can be introduced by zERO or di+art. This context also allows for ART, compare (29) and (22b), (30) and (23b):

(29) a. (Non) ho versato acqua nel bicchiere. NEG have.1SG pour water in the glass

b. (Non) ho versato dell'acqua nelbicchiere. NEG have.1SG be.1SG PA.F.SG water in the glass 'I poured / didn't pour water in my glass.'

(30) a. In questa stanza (non) ci sono zanzare. in this room NEG there are mosquitoes

b. In questa stanza (non) ci sono delle zanzare. in this room NEG there are PA.F.PL mosquitoes 'In this room, there are (no) mosquitoes.'

Note that a definite referential interpretation of the objects in $(22 b)$ and $(23 b)$ is also possible, as they can be synonymous to the sentences in (31), where the object is modified by a relative clause in the indicative, which enforces definite interpretation, parallel to what we find in $(22 \mathrm{c})$ and $(23 \mathrm{c})$ :

(31) a. Hoversato nel bicchiere l'acqua che era nella tua tazza. 'I poured in my glass the water that was in your cup.'

b. In questa stanza ci sono le zanzare che mi hanno punto. 'In this room there are the mosquitoes that bit me.' 
Kind-referring objects can be found in the object position of attitude verbs, such as "love" or "hate" (cf. Laca 199 o for English and Spanish; Anscombre 2001 for French) but cannot be the object of consumption verbs such as "eat" or "drink". This is shown by the contrast between les bananes in (32a) and des bananes in (32b):

(32) a. Les singes aiment les bananes. the monkeys love the bananas 'Monkeys love bananas.'

b. Les singes mangent des bananes. the monkeys love PA.PL bananas 'Monkeys eat bananas.'

In Italian, the contrast is only partially replicated with a major difference, namely, that the article is mandatory in the object of attitude predicates (33), whose object can refer to kind, and optional in the complement of consumption verbs (34), whose object cannot refer to kind as confirmed by the contrast with French (32b), and the pan-Romance overview in (11)-(14) above:

(33) a. Detesto *(il) café. hate.1SG.PRS the coffee 'I hate coffee.'

b. Detesto *(le) ciliegie. hate.1SG.PRS the cherries 'I hate cherries.'

(34) a. Bevo (il) café. drink.1SG.PRS the coffee 'I drink coffee.'

b. Mangio (le) ciliegie. eat.1SG.PRS the cherries 'I eat cherries.'

To conclude, the object position is the most reliable grammatical function to study the variation among bare nominals and overt indefinite determiners. This is because bare nominals cannot appear in subject position unless further modified by an adjective (or other adjuncts). In object position the different 
determiners give different flavours to the notion of indefiniteness to be better defined in the rest of this section. The kind-interpretation of ART can be safely excluded avoiding the predicates that select kind-referring objects, such as attitude verbs. Note that the definite referential interpretation is always possible and must be excluded with appropriate means to be discussed in the following sections.

\subsection{Scope}

As noted by Chierchia (1997), in Standard Italian, bare nominals in direct object position only have narrow scope, while nominals with the "partitive article" may be ambiguous in the plural between narrow and wide scope, like the ones with a singular indefinite article (see also Zamparelli 2008).
(35) a. Non ho
invitato ragazzi.

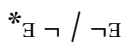
NEG have.1SG.PRS invited boys
'I didn't invite boys.'
b. Non ho
invitato un ragazzo.
$\exists \neg / \neg \exists$
NEG have.1SG.PRS invited a boy
'I didn't invite a boy.'
c. Non ho invitato deiragazzi.
NEG have.1SG.PRS invited PA.M.PL boys
'I didn't invite boys.'

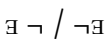

This is supported by the fact that, while (35a) is only compatible with the continuation in $(36 \mathrm{a}),(35 \mathrm{~b}-\mathrm{c})$ are compatible with both continuations in (37) and (38) respectively:
(36) Non ho
invitato ragazzi
NEG have.1SG.PRS invited boys

a. ma solo ragazze.

but only girls

b. \#perchè erano antipatici.

because be.3PL.IMPF unpleasant

'I didn't invite boys but only girls / \# I didn't invite boys because they were unpleasant.' 
(37) Non ho invitato un ragazzo

NEG have.1SG.PRS invited a boy

a. ma una ragazza.

but a girls

b. perchè era antipatico.

because be.3SG.IMPF unpleasant

'I didn't invite a boy but a girl. / \# I didn't invite a boy because he was unpleasant.'

(38) Non ho invitato deiragazzi

NEG have.1SG.PRS invited PA.M.PL boys

a. ma solo ragazze.

but only girls

b. perchè erano antipatici.

घ

because be.3PL.IMPF unpleasant

'I didn't invite boys but only girls / I didn't invite some boys because they were unpleasant.'

Cardinaletti and Giusti (2016) point out that in the dialect of Ancona, the "partitive article" can only have wide scope. This is consistent with the observation that the "partitive article" is not witnessed in point 539 (Ancona) in the AIs maps 637,1037 and 1343, since the noun phrases illustrated in these maps only have narrow scope:

(39) Nun ho

'nvitato deifioli?

NEG have.1SG.PRS invited PA.M.PL boys

a. \#ma solo le fiole.

but only the girls

'I didn't invite boys but only girls.'

7 Laura Brugè notes that here it would be preferable to have the Dom marker $a$ preceding $d e i$ fioli. I agree with her. Although the study of Dом in Anconetano has never been pursued, if we take prepositional accusative to be associated with presupposition of existence, specificity, or wide scope, also in Anconetano, as is the case of other central Italian dialects (see 
b. perché erane 'ntipatici. because be.3PL.IMPF unpleasant 'I didn't invite some boys because they were unpleasant.'

Cardinaletti and Giusti (2016) further claim that mass nouns can only have narrow scope, at least in Italian, as shown in (40):

(40) Non ho bevuto delvino,

NEG have.1SG.PRS invited PA.M.SG boys

a. ho bevuto solo acqua.

have.1SG.PRS dunk only only

'I didn't drink wine. I only drank water.'

b. \#perché era acido.

because be.3sG.PST sour

'I didn't drink wine because it was sour.'

The two claims, that $d i+$ art with mass nouns can only have narrow scope ${ }^{8}$ and that in the dialect of Ancona it can only have wide scope, correctly predict that mass nouns cannot be introduced by the "partitive article" in this dialect. The two claims also predict that in those Italian varieties that allow the "partitive article" with mass and plural nouns, the "partitive article" is ambiguous between wide and narrow scope.

\subsection{Noun Classes}

The different properties of mass and count nouns lead us to the third feature, that is, a finer-grained distinction in the classification of nouns, in particular with regard to their being mass or count.

It is well-known that abstract nouns, such as "courage" and "talent", behave differently from both singular mass and plural count nouns (cf. Tovena 2001). We will not consider them here. We introduce here a less known distinction between singular mass nouns such as pasta and plural nouns that can or must be conceptualized as mass, such as spaghetti and spinaci 'spinach' respectively.

Loporcaro and Paciaroni 2016), this would actually confirm Cardinaletti and Giusti's claim that di+ART in Anconetano can only have wide scope.

8 This is in line with Ihsane's (2008) observation that in French the singular "partitive article" only takes narrow scope, while the plural "partitive article" can have wide or narrow scope. 
The grammaticalized cardinal due 'two' (devoid of cardinal interpretation) can appear with genuine plural count nouns such as amici in (41a) as well as with plural mass nouns such as spaghetti (41b) and spinaci (41c):

\section{(41) a. Ho invitato due amici.}

have.1SG.PRS invited two friends

'I invited two friends.' / 'I invited (a small number of) friends.'

b. Ho preparato due spaghetti.

have.1SG.PRS prepared two spaghetti

'I cooked (some) spaghetti.' / 'I cooked two strings of spaghetti.'

c. Ho raccolto due spinaci.

have.1SG.PRS picked two spinach.M.PL

'I picked (a small quantity of) spinach. / *I picked two pieces of spinach.'

Other low cardinals can be grammaticalized to the point that they occur in idiomatic expressions, for example, tre soldi (lit. three coins, 'little money'), quattro gatti (lit. four cats, 'few people'). Higher cardinals do not have this possibility and can only be interpreted quantificationally.

The quantitative interpretation of cardinals allows us to detect a difference between what we may define as "semantically mass" plural nouns like spinaci in (41c), which can hardly be enumerated, from nouns like spaghetti (41b), which are ambiguous between the "semantic mass" and the regular plural count interpretation (cf. Gerards and Stark, this volume, on mass determiners and nominal plural marking). In fact, with a high cardinal such as 'twelve', which only has the quantitative interpretation, unambiguously semantically mass nouns are not allowed, cf. *dodici spinaci 'twelve spinaches', while ambiguous nouns only have plural interpretation, cf. dodici spaghetti 'twelve [strings of] spaghetti'.

Grammaticalized low cardinals are used as indefinite determiners in all Italian dialects and regional varieties and provide a good alternative to the definite article, which, as pointed out in Section 3.1 above, is three times ambiguous. This is particularly relevant in the study of those varieties that do not allow for the "partitive article" and / or for bare nominals. Grammatically plural but unambiguously semantically mass nouns allow us to distinguish between the determiner and quantitative functions of low cardinals. 


\subsection{Aspect (Telic / Atelic)}

Since Verkuyl $(1972,1993)$, the interpretation of object-referring nominals is strictly related to the aspect of the sentence. The canonical test that allows us to distinguish between telic and atelic (or resultative) aspect is the compatibility with adverbials such as 'in an hour' and 'for hours' respectively. De Swart (2006) reports that Bosveld-de Smet (1998) uses this test as a diagnostic to show that des-NPs in French correlate with atelic interpretation (42), unlike singular un 'a' and plural les 'the', which correlate with telic interpretation (43) (cf. Ihsane, this volume, for a discussion of des-N Ps in telic sentences):

(42) a. Marie a cueilli desfraises pendant des heures.

Marie has picked PA.PL strawberries for PA.PL hours

'Mary picked strawberries for hours.'

b. *Marie a cueilli desfraises en une heure. arie has picked PA.PL strawberries in an hour

(43) a. *Marie a cueilli une fraise / les fraises

Marie has picked a strawberry / the strawberries pendant des heures.

for PA.PL hours

b. Marie a cueilli une fraise/lesfraises en une heure.

Marie has picked a strawberry / the strawberries in an hour 'Marie picked the strawberries in an hour.'

Italian, once again, is different from French in the distribution of the "partitive article" and the definite article, although it behaves like French with respect to the distribution of the indefinite singular article. ${ }^{9}$

In Italian, di+art is almost unacceptable with atelic aspect (44a) and fully possible with telic aspect (44b). ${ }^{10}$ In (45) ART is possible with both aspects, while ZE RO correlates with atelic aspect:

9 In these contexts, the singular count noun preceded by a definite article can only have definite referential interpretation.

10 In this case, I am trusting my personal grammatical judgement. We will come back to this in Section 4.2. 
(44) a. Maria ha raccolto (??delle) fragole perun'ora. Maria has picked PA.F.PL strawberries for an hour 'Mary picked strawberries for an hour.'

b. Maria ha raccolto delle fragole in un'ora. Maria has picked PA.F.PL strawberries in an hour 'Maria picked strawberries in an hour.'

(45) a. Maria ha raccolto (le) fragole / "una fragola per un'ora. Maria has picked the strawberries / a strawberry for an hour 'Maria picked strawberries for an hour.'

b. Maria ha raccolto *(le) fragole / una fragola in un'ora. Maria has picked the strawberries / a strawberry in an hour 'Maria picked the strawberries / a strawberry in an hour.'

The definite article is not ambiguous in (45). With atelic aspect (45a), le fragole 'the strawberries' is synonymous to the bare nominal fragole 'strawberries'; with telic aspect (45), le fragole is a referential definite plural noun phrase.

\subsection{Clause Type}

According to Krifka et al. (1995), generic sentences do not necessarily have arguments that refer to kind, as observed in (11) and (12) above, and, vice versa, kind-referring nominals may be the arguments of non-generic sentences: potatoes in (46a) is the kind referring subject of an episodic sentence; a potato in $(46 \mathrm{~b})$ is the indefinite singular nominal subject of a generic sentence:

(46) a. Potatoes were introduced into Ireland by the end of the 17 th century.

b. A potato contains vitamin $C$, amino acids, protein and thiamine.

We have already observed in Section 2.1 that in Romance languages the definite article introduces kind referring nominals, and only in Italian it can generally introduce indefinite nominals (we call this indefinite determiner ART). Cardinaletti and Giusti (2020) present the results of a questionnaire on the expression of indefiniteness in colloquial Italian and find that ART is much more frequently used in generic negative sentences in the present, such as 'I don't eat meat' and 'I don't drink wine', than in episodic positive sentences in the past, such as 'We ate meat' and 'We drank wine'. Furthermore, in generic sentences $d i+$ art is never present, unlike what is found in episodic sentences, where it is in competition with ZERO and ART. We will get back to this in Section 4.2. 
Polarity is another sentential feature interacting with indefiniteness. Sentence negation allows us to check for the scope of the indefinite object, as observed in (39)-(40) above (cf. Dobrovie-Sorin, this volume, for a discussion of French nominals with a "partitive article" in the scope of negation). In Italian, we have observed that while bare nominals can only have narrow scope, the "partitive article" is ambiguous between narrow and wide scope. This not only holds of positive and negative declaratives (47a-b), but also of questions, as in $(47 \mathrm{c})$ :

(47) a. Ho mangiato (dei) biscotti.

'I ate (some) biscuits.'

b. Non ho mangiato (dei) biscotti.

'I didn't eat (any) biscuits. / I didn't eat some biscuits.'

c. Hai mangiato (dei) biscotti?

'Did you eat (any) biscuits? / Did you eat some biscuits?'

In a variety which only allows for wide scope of $d i+$ art, such as Anconetano, $(47 \mathrm{c})$ is expected to be felicitous only in the interpretation in which the existence of biscuits that I did not eat is presupposed. This is because Anconetano only allows for the wide scope interpretation of $d i+$ art. This prediction is borne out, at least in my native speaker capacity.

Mood and modality generally interact with the presupposition of existence of the referent of the indefinite complement. A predicate in a conditional clause does not state the existence of its internal argument. The Italian sentences in (48) are equally felicitous whether I have in mind some specific biscuits or friends (strong interpretation) or not (weak interpretation):

(48) a. Mangerei (dei) biscotti.

'I would eat (some) biscuits.'

b. Arriverebbero (delle) amiche.

'There would arrive (some) friends.'

This also holds of relative clauses in the subjunctive mood, which strongly favour the weak interpretation of the object of predicates such as "look for" or "wish":

(49) a. Cerco (dei) biscotti che non facciano ingrassare. 'I am looking for (some) biscuits that do not make you fat.'

b. Desidero (delle) amiche che mivogliano bene. 'I wish [to have] (some) friends who love me.' 
In Anconetano, the contexts enforcing narrow scope, such as those in (49) are predicted to be ungrammatical. This is borne out in my native speaker judgement. Fieldwork is needed to confirm this judgement.

\subsection{Specialization of Meaning}

Cardinaletti and Giusti (2018) argue that the different distribution of ZERO, ART, bare $d i$, and $d i+$ art in given areas of the Italian territory can be due to different specializations of meaning associated to weak indefinites. The examples corresponding to the AIs map 1037 '[if there was] water' have the largest occurrence of bare nominals, because a mass noun in postverbal subject position of an existential predicate in a conditional sentence does not trigger any special meaning. ZERO thus represents the core form to express uncontroversial indefinites. ART occurs more often in the AIs map 1343 '[go to the cellar] to take wine', because wine is the typical substance stored in a cellar and this suggests that ART specializes for saliency. $D i+$ art occurs more often in the AIS map 637 '[to look for] violets', because violets are usually picked in small quantities, a notion encoded by the "partitive article" in those Italian dialects that display it. This proposal was based on our personal intuitions and needs to be confirmed by the metalinguistic observations of a larger number of native speakers. This is one of the aims of the questionnaire presented in Section 4.

It is well-known that different indefinite determiners convey different types of indefiniteness. The semantic literature is abundant in distinguishing "identifiability" of an indefinite referent in epistemic Logic (Horn 200o; Jayez and Tovena 2002). It is therefore expected that coexisting determiners specialize for different interpretations. What is difficult to establish is what exactly these specializations are and how they correlate with the other features interacting with indefiniteness. One case in point in our repertory of indefinite determiners is certo "certain". Certo is present in all Italian varieties. It combines with the indefinite article (una certa persona, 'a certain person') with count singular nouns, but behaves as a determiner, therefore competes with di+art and ART,

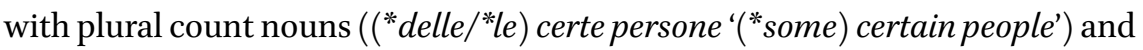
mass nouns $\left(\left({ }^{*}\right.\right.$ della $\left./{ }^{*} l a\right)$ certa carne 'certain meat'). Given that certo is reported to have core indefinite meaning in some southern Italian dialects, as in $(20)$ in Section 2.2, the issue arises as to whether it can be a core indefinite in certain varieties.

\subsection{Collocation (Frequency of Possible Predicate-Object Combinations)}

The notion of saliency does not only concern our encyclopedic knowledge and shared assumptions; it also regards the frequency with which the predicate and direct object (or other arguments) combine in the same collocation. For 
example, "eat meat" or "drink water/wine" are supposedly more frequent and certainly more general than "eat potatoes" or "drink spirits". The issue of the frequency of the verb-noun collocations is an important matter that requires a separate dedicated search in large corpora of Italian. Such corpora are unfortunately not available for Italian dialects and comparison across regional varieties of Italian and local Italo-Romace varieties would be impossible in this respect.

A "protocol" in science is an established procedure, which applies in the same way with the same tools in different but comparable situations. It is therefore set to ensure comparability in experimental design and the collection, organization, and presentation of data avoiding disturbances, as far as this is possible. General linguistics is used to expressing correlations across phenomena and languages in table charts that display a +/- value. In Giusti (2011), I propose to turn this shared procedure of data representation into something more reflected and structured, which I call a "protocol". The protocol methodology aims to go one step further in the appropriate design of the table charts, presenting the features of the elements under investigation in a reflected way. In the streamline of the search for parameters or implicational universals, the features of the protocol can be organized in clusters of properties that contribute to the understanding of parameter hierarchy and parametric variation. ${ }^{11}$

In this section, I give examples on how to transfer the empirical observations presented in Section 3 into the protocol methodology, in order to answer our two basic research questions: Have modern dialects changed due to contact with Italian? And conversely, does colloquial Italian display contact with the local dialects? In Section 4.1, I set the protocols; in Section 4.2, I present a questionnaire built on the protocols and the results of the questionnaire submitted to Italian native speakers; in Section 4.3, I present the results of pilot adaptations of the same questionnaire to some Italian dialects.

11 The protocol methodology has been applied to the study of Romance-Slavic contact in Istro-Romanian, a severely endangered Romance language in Croatia, with the aim to enhance inclusive language awareness by Giusti and Zegrean (2015). It has been applied to the comparative teaching of psychological verbs in classical and modern languages (Latin and English) to Italian students by Giusti and Iovino (2016). It has also been applied in dialectological fieldwork on the Sicilian pseudo-coordination construction by Di Caro and Giusti (2015) and Di Caro (2019). 


\subsection{A Protocol for Indefinite Determiners in Italo-Romance}

In Table 8.1 we find a simple protocol that can be applied to any Romance language to establish the distribution of the various indefinite determiners found in that language. The horizontal axis is filled with six determiners in nondialectal informal Italian among those presented in Section 2.2 (but we could have more). The vertical axis presents the three main noun classes we adopt. Here we could be more detailed, as regards noun subclasses, as we have seen for spaghetti and spinaci in (41) above. For each property we attribute a value: $[+]$ indicates that the form is present, [-] that it is absent, and [\#] that it exists but has a different interpretation: ${ }^{2}$

The determiners in Table 8.1 interact with the other features discussed in Section 3. Let us start with the observations we made about the grammatical functions of the nominal phrase. These functions are represented in Table 8.2, where the value [o] indicates that the feature is not relevant. We take bare $d i$ to be irrelevant, because it is attributed a [-] for each noun class in Table 8.1: ${ }^{13}$

We can look for possible specializations of meaning as discussed in Sections 2.2, 3.2 and 3.6. The protocol in Table 8.3 displays the value [?] for unchecked items. This means that we do not have an answer to the following research questions expressed in the protocol: How does the grammaticalized determiner due behave with respect to the different specialized meanings of indefiniteness seen in Section 3 ? Is it restricted to core meaning? Is it used for small quantity (as is probably the case, if I can trust my personal judgement)? Is it compatible with specific interpretation? Does it display scope ambiguities, like $d i+$ art? Appropriate fieldwork is needed to answer these questions.

12 In (a) in Table 8.1, un occurring with a mass noun turns it into a count noun. In (c) in Table 8.1 ART occurring with a singular count noun can only have definite interpretation. The values given in Table 8.1 are based on the discussion on Italian in Section 3. It remains to be checked in all Italo-Romance varieties (as will be briefly presented in Section 4.3 below).

13 Here we abstract away from bare nominals in dislocated positions, which are mandatorily preceded by bare $d i$ in right dislocation structures and optionally so in left dislocations structures, see Cardinaletti and Giusti (2017) for a detailed discussion of quantitative constructions:

(i) Ne ho viste molte, *(di) ragazze!

=PART have.1SG seen many.F.PL of girls

'I saw many, girls.'

(ii) (Di)Ragazze, ne ho viste molte.

of girls, =PART have.1SG seen many.F.PL

'Girls, I saw many.' 
TABLE 8.1 Protocol for the distribution of indefinite determiners

\section{Indefinite determiners in Italian ZERO ART di di+art certo un due}
a. mass nouns
b. plural count nouns
c. singular count nouns

TABLE 8.2 Protocol for the grammatical functions of the nominal phrases

\section{Indefinite determiners across ZERO ART bare di di+art certo un due grammatical functions in Italian}
a. preverbal subject
b. direct object

TABLE 8.3 Protocol for specialized meanings of indefiniteness

Indefinite determiners in object ZERO ART bare di di+art certo uno due position in Italian
a. core indefiniteness
b. saliency
c. small quantity
d. specificity
e. narrow scope
f. wide scope

$\begin{array}{ccccccc}+ & + & 0 & - & - & + & + \\ - & + & 0 & - & - & + & ? \\ - & - & 0 & + & - & - & ? \\ - & - & 0 & + & + & + & ? \\ + & + & 0 & + & ? & + & ? \\ - & \# & 0 & + & + & + & ?\end{array}$

In Sections 3.4 and 3.5, we discussed sentence types and different properties of the predicate. The questionnaire illustrated in Sections 4.2 and 4.3, only includes present vs. past tense associated to generic vs. episodic sentences and telic vs. atelic aspect. For this reason, protocol in Table 8.4 nests Tense (present / past) and Aspect (telic vs atelic) as sub-features of sentence types (generic vs episodic). The values filling the protocols in Tables 8.1-8.4 refer to the discussions in the literature and in some cases to my own judgement: 
Sentence types interacting with ZERO ART bare di di+art certo uno due indefinite objects in Italian

a. generic sentences

$\begin{array}{lllllllll}\text { i. present } & + & + & 0 & - & - & + & ? \\ \text { ii. past } & ? & ? & 0 & ? & ? & ?\end{array}$

b. episodic sentences
i. present
ii. past

c. episodic sentences

i. atelic

ii. telic

Generativists are often criticized because they rely on few native speakers' judgements and do not check these judgements on a larger scale. This would enable us to observe that judgements are not as categorical as presented in the generative literature. The protocol approach is precisely meant to transfer theoretical claims such as the ones reported in Section 3 into a tool for empirical research (the questionnaire) to detect variation and optionality in the distribution of indefinite determiners and provide a widely accessible presentation of the results.

\subsection{A Questionnaire Based on the Protocol}

This section presents the design of a questionnaire meant to check a subset of all possible combinations of the properties arising with indefiniteness as highlighted in the four protocols discussed in the previous section. The questionnaire was made of 25 items:

- 9 items presenting multiple possibilities for direct objects (singular mass vs. count plural) to express indefiniteness in different contexts (tense / aspect / polarity).

- 2 open substitution tasks, asking the participant to replace a singular mass noun encountered in the previous context with a plural count noun.

- 6 open comments on possible differences in interpretation, in case the participant selected more than one choice, to collect metalinguistic observations.

- 4 items asking the participant to judge the coherence of statements with a follow-up causative clause, to check the occurrence of determiners in narrow vs. wide scope. 
- 3 open questions on the linguistic attitude of the participant (confidence in their judgments, their normative vs. descriptive attitude, their personal appreciation of the experience of completing the task).

- The last item requested the consensus to use the data in anonymized form. The items were administered in a fixed order with no fillers. ${ }^{14}$ This made the questionnaire as short and accessible as possible, allowing the participants to "warm up" with the shorter and simpler sentences and to complete the more engaging tasks without getting tired towards the end of the session. All instructions and items where provided in Italian. In Table 8.5, I provide the English glosses and the variation among the five determiners in order to save space but mind that each item of the table was spelled out as 5 full sentences: ${ }^{15}$

TABLE 8.5 Illustration of a questionnaire, in English

1. In your variety of informal Italian, a vegetarian would say:

I don't eat o/the/of/PA/certain meat.

2. Please substitute 'meat' with 'potatoes'.

3. In your variety of informal Italian, a teetotaller would say:

I don't drink o/the/of/PA/certain wine.

4. Please substitute 'wine' with 'spirits'.

5. Talking about the menu at a dinner party yesterday, you would say:

We ate o/the/of/PA/certain meat.

6. If you allowed more than one choice in the previous answer, do you find any difference among them? If so, please explain.

7. Talking about a toast among friends yesterday, you would say: We drank o/the/of/PA/certain wine.

8. If you allowed more than one choice in the previous answer, do you find any difference among them? If so, please explain.

9. Suggesting what one could do in the mountains, one could say:

You can pick o/the/of/PA/certain violets.

10. If you allowed more than one choice in the previous answer, do you find any difference among them? If so, please explain.

14 For reasons of space we refer the reader to Cardinaletti and Giusti (2020) for the detailed presentation of the methods of administration of the questionnaire and the linguistic profiles of the participants.

15 The questionnaire is meant to detect the rate of optionality among five possible forms: ZERo (o), ART, bare di, di+art (PA), and certo. The possibility to choose more than one option is designed to answer the following research questions: What is the rate of optionality? How is it distributed across regional Italian? How do competing forms distribute across contexts? 
TABLE 8.5 Illustration of a questionnaire, in English (cont.)

11. Carefully read the sentences to the end and only chose those that you find internally consistent. To my party, ...

I didn't invite o/the/of/PA/certain boys but only girls.

12. Carefully read the sentences to the end and only chose those that you find internally consistent. To my party, ...

I didn't invite o/the/of/PA/certain boys because they were unpleasant.

13. I am telling what I did last Sunday in the open air.

a. I cut o/the/of/PA/certain grass for an hour.

b. I cut o/the/of/PA/certain grass in an hour.

14. If you allowed more than one choice in the previous answer, do you find any difference among them? If so, please explain.

15. Still telling what you did last Sunday to spend time in the open air, you would say:

a. I picked o/the/of/PA/certain blueberries for an hour.

b. I picked o/the/of/PA/certain blueberries in an hour.

16. If you allowed more than one choice in the previous answer, do you find any difference among them? If so, please explain.

17. Carefully read the sentences to the end and only chose those that you find internally consistent. Today, at lunch,

I didn't drink o/the/of/PA/certain water because it tested like chlorine.

18. Carefully read the sentences to the end and only chose those that you find internally consistent. Today, at lunch,

I didn't drink o/the/of/PA water but only wine.

19. If you allowed more than one choice in the previous answer, do you find any difference among them? If so, please explain.

20. Complete the sentences: While Gianni was setting the table in the garden ... Maria went to the cellar to take o/the/of/PA wine.

21. and in the meantime, ...

Teresa went to the butcher's to buy o/the/of/PA beefsteaks.

22. Reflecting upon your attitude in filling in the questionnaire, please chose one: I had no doubts. I had some doubts. I was not sure of my judgements.

23. What competence did you rely upon in answering the questions? knowledge of the Italian native competence of native competence of grammar the high register regional Italian

24. How did you like answering the questionnaire?

It made me think of

It was boring and repetitive:

phenomena I had never noted. I see no point in doing it. 
TABLE 8.6 Combination of features

\begin{tabular}{|c|c|c|c|c|c|c|c|c|c|}
\hline Item & $\begin{array}{l}\text { Sentence } \\
\text { type }\end{array}$ & Tense & Polarity & $\begin{array}{l}\text { Noun } \\
\text { class }\end{array}$ & $\begin{array}{l}\text { Frequency in } \\
\text { collocation }\end{array}$ & $\begin{array}{l}\text { Special } \\
\text { meaning }\end{array}$ & $\begin{array}{l}\text { Presupposition } \\
\text { of existence }\end{array}$ & Telicity & Task \\
\hline 1 & GEN & PRES & NEG & MASS & high & NO & NO & NO & 5-choices \\
\hline 2 & GEN & PRES & NEG & PL & high & NO & NO & NO & open Q \\
\hline 3 & GEN & PRES & NEG & MASS & mid-high & NO & NO & No & 5-choices \\
\hline 4 & GEN & PRES & NEG & PL & mid-low & NO & NO & NO & open Q \\
\hline 5 & EPIS & PAST & POS & MASS & high & YES/NO & YES/NO & YES/NO & 5 -choices \\
\hline 7 & EPIS & PAST & POS & MASS & high & YES/NO & YES/NO & YES/NO & 5-choices \\
\hline 9 & EPIS & PRES & POS & PL & mid-low & YES/NO & NO & NO & 5 -choices \\
\hline 11 & EPIS & PAST & NEG & PL & high & NO & NO & NO & 5-choices \\
\hline 12 & EPIS & PAST & NEG & PL & mid-high & YES/NO & YES & NO & 5-choices \\
\hline $13 a$ & EPIS & PAST & NEG & MASS & high & YES/NO & YES/NO & NO & 5-choices \\
\hline $13 \mathrm{~b}$ & EPIS & PAST & NEG & MASS & high & YES/NO & YES/NO & YES & 5 -choices \\
\hline $15^{a}$ & EPIS & PAST & NEG & PL & mid & YES/NO & YES/NO & NO & 5 -choices \\
\hline $15^{b}$ & EPIS & PAST & NEG & PL & mid & YES/NO & YES/NO & YES & 5-choices \\
\hline 17 & EPIS & PAST & NEG & MASS & high & No & YES & NO & 5-choices \\
\hline 18 & EPIS & PAST & NEG & MASS & high & NO & NO & NO & 4-choices \\
\hline 20 & EPIS & PAST & POS & MASS & high & YES & YES/NO & NO & 4-choices \\
\hline 21 & EPIS & PAST & POS & PL & mid-high & YES & YES/NO & NO & 4-choices \\
\hline
\end{tabular}

The combinations of features to be investigated are spelled out in Table 8.6. In the first column, we find the item numbers of Table 8.5. In the last column, we find the type of task that was used to collect the data. Items [13] and [15] were split according to the different value of telicity to be checked. Items [18], [20] and [21] did not have the choice with certo. The [YES], [NO], [YES/NO] values should be read as follows: [YES]: the feature is positively enforced in the stimulus; [NO]: the feature is negatively enforced in the stimulus; [YES/NO]; the feature is not enforced in the stimulus. The value for frequency of the collocation are arbitrary estimations and need to be checked.

Cardinaletti and Giusti's (2020) quantitative study of items $\left[1-4,5^{-7}\right]$ shows that ZERO and ART are the most common. ZERO is more often used than ART in negative generic sentences in the present [1-4]. ART is more often used than ZERO in positive episodic sentences in the past $[5,7]$. Bare di never appears in non-dialectal informal Italian. Di+art and certo do not occur in generic sentences, thereby confirming their specialized meanings.

Table 8.7 reports the results of the whole questionnaire. Recall that it was possible to choose more than one possibility; all cells could in principle be filled with the value $100 \%$. Any deviation from this percentage means that some participants did not find the determiner appropriate: 
TABLE 8.7 Results of the questionnaire

\begin{tabular}{|c|c|c|c|c|c|c|c|c|c|}
\hline \multirow{2}{*}{$\begin{array}{l}\text { Item } \\
1\end{array}$} & ZERO & \multicolumn{2}{|c|}{ ART } & \multicolumn{2}{|c|}{ bare $d i$} & \multicolumn{2}{|c|}{$d i+$ art } & \multicolumn{2}{|c|}{ certo } \\
\hline & $69 / 82 \quad 84 \%$ & $57 / 82$ & $69 \%$ & o/82 & ०\% & $2 / 82$ & $2 \%$ & $2 / 82$ & $2 \%$ \\
\hline 2 & $66 / 82 \quad 80 \%$ & $75 / 82$ & $92 \%$ & o/82 & ०\% & $3 / 82$ & $3 \%$ & $10 / 82$ & $12 \%$ \\
\hline 3 & $76 / 82 \quad 93 \%$ & $49 / 82$ & $59 \%$ & $\mathrm{o} / 82$ & ०\% & $3 / 82$ & $3 \%$ & $1 / 82$ & $1 \%$ \\
\hline 4 & $78 / 82 \quad 96 \%$ & $46 / 82$ & $56 \%$ & $\mathrm{o} / 82$ & ०\% & $3 / 82$ & $3 \%$ & $7 / 82$ & $8 \%$ \\
\hline 5 & $66 / 82 \quad 80 \%$ & $43 / 82$ & $53 \%$ & o/82 & ०\% & $37 / 82$ & $45 \%$ & $2 / 82$ & $2 \%$ \\
\hline 7 & $56 / 82 \quad 68 \%$ & $37 / 82$ & $45 \%$ & $\mathrm{o} / 82$ & ०\% & $44 / 82$ & $53 \%$ & $6 / 82$ & $7 \%$ \\
\hline 9 & $50 / 82 \quad 60 \%$ & $66 / 82$ & $80 \%$ & $\mathrm{o} / 82$ & ०\% & $40 / 82$ & $49 \%$ & $6 / 82$ & $7 \%$ \\
\hline 11 & $74 / 82 \quad 91 \%$ & $22 / 82$ & $27 \%$ & $3 / 82$ & $3 \%$ & $25 / 82$ & $30 \%$ & $8 / 82$ & $10 \%$ \\
\hline 12 & $16 / 82 \quad 19 \%$ & $5^{2 / 82}$ & $64 \%$ & $1 / 82$ & $1 \%$ & $40 / 82$ & $49 \%$ & $62 / 82$ & $76 \%$ \\
\hline $13 a$ & $36 / 82 \quad 44 \%$ & $75 / 82$ & $92 \%$ & $\mathrm{o} / 82$ & ०\% & $22 / 82$ & $27 \%$ & $9 / 82$ & $11 \%$ \\
\hline $13 b$ & $4 / 82 \quad 5 \%$ & $55 / 82$ & $67 \%$ & $\mathrm{o} / 82$ & ०\% & $15 / 82$ & $18 \%$ & $8 / 82$ & $10 \%$ \\
\hline $15^{a}$ & $70 / 82 \quad 85 \%$ & $5^{6 / 82}$ & $68 \%$ & $\mathrm{o} / 82$ & ०\% & $27 / 82$ & $33 \%$ & $12 / 82$ & $15 \%$ \\
\hline $15^{b}$ & $11 / 82 \quad 14 \%$ & $5^{\circ / 82}$ & $61 \%$ & $\mathrm{o} / 82$ & ०\% & $25 / 82$ & $30 \%$ & $12 / 82$ & $15 \%$ \\
\hline 17 & $47 / 82 \quad 57 \%$ & $72 / 82$ & $88 \%$ & $3 / 82$ & $3 \%$ & $12 / 82$ & $15 \%$ & $11 / 82$ & $13 \%$ \\
\hline 18 & $72 / 82 \quad 88 \%$ & $29 / 82$ & $35 \%$ & o/82 & ०\% & $26 / 82$ & $32 \%$ & & $\mathrm{x}$ \\
\hline 20 & $11 / 82 \quad 13 \%$ & $77 / 82$ & $94 \%$ & $\mathrm{o} / 82$ & ०\% & $5^{6 / 82}$ & $68 \%$ & & $\mathrm{x}$ \\
\hline 21 & $12 / 82 \quad 15 \%$ & $76 / 82$ & $93 \%$ & $\mathrm{o} / 82$ & ०\% & $43 / 82$ & $53 \%$ & & $\mathrm{x}$ \\
\hline
\end{tabular}

In Table 8.7, only ZERO and ART massively appear in all contexts. ZERO has the highest preference $(\geq 80 \%)$ in items $[1,2,3,4,5,11,15 \mathrm{a}, 18]$. ART has the highest preference $(\geq 80 \%)$ for items $[2,9,13 \mathrm{a}, 17,20,21]$. ART prevails over ZERO in the two telic contexts [13 b, 15b], and the contexts with salient objects: [20] ("wine" salient to cellar); [21] ("beefsteaks" salient to the butcher's); [9] ("violets" salient to mountains). Another saliency context is item [2]: according to the comments collected in item 3, "potatoes" was interpreted by many participants as salient to a hypernym "vegetables" (to be contrasted to "meat" found in the previous item). Finally, item [13a] presumably presents a highly frequent collocation of the predicate "cut" with the mass noun "grass", which favours ART, even if ZERO is robustly present.

$D i+$ art is virtually absent $(\leq 3 \%)$ in generic negative sentences in the present [1-4]. It is more frequently chosen (between $45 \%$ to $68 \%$ ) in items $[5,7,9$, $12,20,21]$, which favour small quantity interpretation: wine is drunk in small quantity $[5,7,20]$, violets can be collected in small bunches [9], steaks for a dinner are certainly bought in the appropriate (small) quantity [21]. It is mildly chosen $(27-33 \%)$ in narrow scope contexts [11] and [18], in atelic con- 
texts [13a, 15a], and with small objects, such as blackberries [15a-b] independently of telicity. It is possible but less popular $(15 \%-18 \%)$ with mass nouns with a telic predicate [13b] or with presupposition of existence (wide scope) [17]. It is interesting to contrast item [12], which enforces presupposition of existence of plural count nouns and has di+art chosen by $49 \%$ of the speakers and item [11], which disfavours presupposition of existence of plural count nouns, and is chosen only by $30 \%$ of the speakers. This confirms the ambiguity of $d i+a r t$ between wide and narrow scope, and the preference of some speakers to only use it with wide scope. Note that the results of the questionnaire partially contradict my judgement of (44a), which ruled out the "partitive article" in narrow scope contexts. My judgement was in fact representative of my central Italian competence in contact with Anconetano (my native dialect).

The distribution of certo was only tested in items [1-17]. According to the comments collected in items $[6,8,10,14,16]$, certo is interpreted as either specifying the intension (a specific type of $\mathrm{N}$ ) or the extension, that is as denoting a specific referent. This is confirmed by the observation that certo is the most chosen determiner in item [12], which not only presupposes the existence of the referent but also provides a context to pick specific (types of) individuals (with the characteristic of unpleasantness), as stated in the continuation of the sentence ("... because they were unpleasant"). More research is needed to establish whether it is appropriate to distinguish the specification of the referent as opposed to the specification of the type.

\subsection{A Pilot Adaptation of the Questionnaire to Italo-Romance Dialects}

The protocol methodology is designed to capture cross-linguistic variation. It would be desirable to translate the questionnaire into individual dialect points or areas across the Italian territory. The values in Table 8.8 are the results of pilot studies conducted by students of the MA programme in Language Sciences at Ca' Foscari University of Venice, attending my Comparative Syntax class in the academic years 2017-2018 and 2018-2019. The dialects investigated partially cover the Italian territory: Campomolino (TV), Furlan (2018); southern Friulian (Castions di Strada, Pocenia and Gonars, UD), Perinot (2018); Piacenza, Molinari (2018); Altamura (BA), Vicenti (2019); the Neapolitan area (Casalnuovo, Casoria, Soccavo, Bagnoli, Pozzuoli, Santa Lucia, San Ferdinando, Vasto Napoli, Somma Vesuviana, Frattamaggiore), Procentese (2019); Galati (RC), Maesano (2019); Lecce, Antonaci (2018). The Ancona dialect is represented by my own judgements and needs proper fieldwork but is inserted here to represent a central variety. Totally missing areas are the North-West, Sicily and Sardinia. Despite these areal gaps, the organization of the protocol allows us to con- 
TABLE 8.8 Results of pilot studies conducted by MA students

\section{Core indefinites in object position zERO ART bare di di+art certo un}
a. Campomolino (TV)
b. Southern Friulian (UD)
c. Piacenza
d. Ancona
e. Altamura (BA)
f. Neaples area
g. Galati (RC)
h. Lecce

$+\quad(+) \quad-$

$(+)$

(+) $\quad+$

$\begin{array}{ccl}+ & + & - \\ (+) & + & \mathrm{NEG}>+ \\ - & + & - \\ - & + & - \\ (+) & + & - \\ + & + & - \\ + & (+) & -\end{array}$

(+)

(+) +

$(+)+$

$(+) \quad(+) \quad+$

- $\quad+$

- $\quad(+) \quad+$

- $(+)+$

\section{h. Lecee}

firm some of Cardinaletti and Giusti's (2018) generalizations on Italian dialects, based on the AIS maps, and Cardinaletti and Giusti's (2020) generalizations on informal Italian, based on the first 6 items of the questionnaire. The straight + /- value indicates that the form is present or absent. The value in parenthesis indicates that it is present only in some contexts.

The "partitive article" di+art is only present in Gallo-Romance varieties, mostly in Emilia (Piacenza), where it can have core indefinite meaning (as indicated by a straight [+]). In the rest of the North (Friulian and Campomolino), $d i+$ art is possible, as in Italian, only in episodic contexts, as indicated by the parenthesized $[(+)]$ value. In the South $d i+$ art is totally absent, as indicated by a straight [-] value.

Bare $d i$ is possible in the dialect of Piacenza in the scope of negation, as represented by $[\mathrm{NEG}>+]$. The dialect of Piacenza can thus be considered as the area in which bare $d i$ covaries with $d i+$ art to express core indefiniteness. Cerruti and Regis (2020) report the possibility of bare di in object position in modern Piedmontese (cf. Stark and Gerards, this volume, on Francoprovençal, which has a bare DE in many contexts). In future research, an adaptation of our questionnaire to Piedmontese will allow us to ascertain whether it coexists with other forms, and if so, how the coexisting forms distribute in the different contexts.

Note that in no dialect, not even the southern ones, have we detected the use of certo with core indefinite interpretation, which is reported by Rohlfs (1968, $118)$ and Giammarco $(1979,141)$. The sparseness of our data may well be the reason of this gap. Research on other areas of the South is needed to check the survival of this form, which is in strong competition with itself in the specialized meaning of specific interpretation. 
ZERO is not only absent in the central dialect of Ancona, but, surprisingly, even in the southern dialect of Altamura (central Apulia). Note that in Piacenza and Neaples, it is possible but not favoured as indicated by the value in parentheses $(+)$. ZERO is the unmarked determiner at the extreme South (Lecce (southern Apulia) and Galati (Southern Calabria)) and in the North (Venetan dialect of Campomolino and Friulian). This confirms the hypothesis of the North-South isogloss of ART in indefinite nominals surrounded by the area in which ZERO has core indefinite interpretation and ART is limited to special readings (namely the ones involving saliency or in generic sentences).

The protocol methodology proposed in the previous section is nothing else than a meta-theoretical way to formulate the research questions raised by the theoretical advances in syntactic and semantic literature presented in Sections 2 and 3 in a structured fashion and without resorting to theory internal assumptions and technicalities. The questionnaire based on the protocol allowed us to detect variation and fine-grained dimensions of optionality in the occurrence of five indefinite determiners, that had up to now been discussed separately and at different levels of intensity in the literature.

The highlight of the present contribution lies in a systematic observation of the properties of the grammaticalized form of the definite article with indefinite interpretation, ART, which distinguishes Italo-Romance from most other Romance languages and varieties. This is conducted in a comparative perspective with the other, better described, indefinite determiners, that is the "partitive article", and the ZERO determiner or absence of determiner in bare nouns.

The administration of the pilot questionnaire in Italian and in different Italian dialects allowed us to formulate preliminary answers to the two urgent questions arising from the observation of variation and optionality in indefinite determiners in Italo-Romance: What is the distribution of indefinite determiners in modern Italian dialects in contact with Italian? What is the distribution of indefinite determiners in regional varieties of modern Italian in contact with the local dialects?

What emerges from the discussion is that all regional varieties of modern Italian have the four determiners (ZERO, ART, di+art and certo) with a sort of homogeneous specialization of functions. It also emerges that local dialects have maintained their characteristics, which can be highlighted as absence of ZERO irradiating from the centre in the North-South direction, and absence of $d i(+$ art) below the Gothic line (the dialect of Ancona). Interestingly, the dialect 
of Piacenza marks the upper area of the use of ZERO, even if it is fully included in the area delimited by ART. Note that Piacenza is in the area where $d i+$ art is also used for core indefiniteness and interestingly provides the only evidence found so far of the use of bare di in argument position, limited to objects in the scope of negation.

The systematic empirical research done in the protocol methodology allows us to come back to the theoretical dimension. The dialect of Piacenza confirms Cardinaletti and Giusti's $(2016,2018)$ hypothesis that the four determiners ZERO, ART, bare $d i$, and $d i+$ art are structurally derived by the overt/covert realizations of two positions in the Determiner Phrase (DP) of indefinite expressions: SpecDP can have a covert indefinite determiner or an overt counterpart $d i$, while D can have a covert realization of nominal features (gender and number) or an overt counterpart of it (formally the grammaticalized definite article). The two options are areally distributed as two independent isoglosses. The dialect of Piacenza, being at the crossroad of the two isoglosses, has the four options. The other dialects have more limited possibilities. Only GalloRomance allows for di in SpecDP which may occur with a null D (as in Piedmontese) or require the overt realization of D resulting in the "partitive article" $d i+$ art. Central dialects lacking bare nouns have a covert indefinite determiner in SpecDP requiring $\mathrm{D}$ to be overt.

\section{Acknowledgements}

I thank Larisa Avram, Ana Maria Brito, Mihaela Dogaru, M. Teresa Espinal, Angel Gallego, Tabea Ihsane, Jaklin Kornfilt, XavierVillalba, and Elisabeth Stark for discussion and constructive criticism. I also thank Claudia Antonaci, Erica Furlan, Debora Maesano, Luca Molinari, Lara Perinot, Cristina Procentese and Rosa Vicenti for their expertise and enthusiasm in translating the questionnaire, collecting the dialectal data and for their knowledge in analyzing them. Finally, I thank Anna Cardinaletti with whom I have been working on this topic in the last ten years and Laura Brugè who has commented the first draft.

\section{References}

AIS = Jaberg Karl, Jud Jakob, Sach- und Sprachatlas Italiens und der Südschweiz, Zofingen, Ringier, 1928-1940.

Anscombre, Jean-Claude. 2001. "Le rôle du lexique dans la théorie des stéréotypes". Langages 142: 57-76. 
Antonaci, Claudia. 2018. "On indefiniteness and the distribution of indefinite determiners in Salento”. Term paper, MA in Language Sciences, Ca' Foscari University of Venice.

Berruto, Gaetano. 1974. Piemonte e Valle d'Aosta. Pisa: Pacini.

Bosveld-de Smet, Leonie. 1998. On Mass and Plural Quantification: The case of French 'des'/'du' N Ps. PhD. dissertation, University of Groningen.

Brasoveanu, Adrian, and Donka F. Farkas. 2016. "Indefinites." In The Cambridge Handbook of Formal Semantics, edited by Maria Aloni and Paul Dekker, 238-266. Cambridge: Cambridge University Press.

Cardinaletti, Anna, and Giuliana Giusti. 2016. “The Syntax of the Italian determiner dei." Lingua 181: 58-8o. https://doi.org/10.1016/j.lingua.2016.05.001.

Cardinaletti, Anna and Giuliana Giusti. 2017. "Quantified expressions and quantitative clitics." In The Wiley Blackwell Companion to Syntax, edited by Martin Everaert and Henk C. Van Riemsdijk, Second Edition, 1-61. London: Wiley Blackwell. https://doi .org/10.1002/9781118358733.wbsyncomo63

Cardinaletti, Anna, and Giuliana Giusti. 2018. "Indefinite Determiners: Variation and Optionality in Italo-Romance." In Advances in Italian Dialectology, edited by Diego Pescarini and Roberta D'Alessandro, 135-161. Language and Linguistics EBooks Online. doi: 10.1163/9789004354395_oo8.

Cardinaletti, Anna, and Giuliana Giusti. 2020. "Indefinite determiners in informal Italian. A preliminary analysis." In Shades of Partitivity: formal and areal properties, edited by Tabea Ihsane and Elisabeth Stark. Special Issue in Linguistics 58, no. 3: 679-712. https://doi.org/10.1515/ling-2020-0o81.

Carlier, Anne. 2007. "From preposition to article. The grammaticalization of the French partitive." Studies in Language 31, no.1: 1-49. doi: 10.1075/sl.31.1.o2car.

Carlier, Anne, and Béatrice Lamiroy. 2014. "The Grammaticalization of the Prepositional Partitive in Romance." In Partitive Cases and Related Categories, edited by Silvia Luraghi and Tuomas Huumo, 477-520. Berlin: de Gruyter.

Carlier, Anne, and Béatrice Lamiroy. 2018. "The emergence of the grammatical paradigm of nominal determiners in French and in Romance: Comparative and diachronic perspectives." Canadian Journal of Linguistics 63, no. 2: 141-166.

Cerruti, Massimo, and Riccardo Regis. 2020. "Partitive determiners in Piedmontese: a case of language variation and change in a contact setting." In Shades of Partitivity: formal and areal properties, edited by Tabea Ihsane and Elisabeth Stark. Special Issue in Linguistics 58, no. 3: 651-677.

Chierchia, Gennaro. 1997. "Partitives, referents to kinds and semantic variation." In SALT 7 Proceedings, edited by Aaron Lawson, 73-98. Ithaca, NY: Cornell University.

De Swart, Henriëtte. 2006. "Aspectual implications of the semantics of plural indefinites." In Non-definiteness and plurality, edited by Svetlana Vogeleer and Liliane Tasmowski, 161-189. Amsterdam: John Benjamins. 
Delfitto, Denis, and Jan Schroten. 1991. "Bare Plurals and the Number Affix in DP." Probus 3, no. 2: 155-185. https://doi.org/10.1515/prbs.1991.3.2.155.

Di Caro, Vincenzo. 2019. Multiple Agreement constructions in southern Romance. The syntax of Sicilian pseudo-coordinations. PhD dissertation, Ca' Foscari University of Venice.

Di Caro, Vincenzo, and Giuliana Giusti. 2015. "A protocol for the Inflected Construction in Sicilian dialects." Annali di Ca' Foscari. Serie Occidentale, 49: 293-322. http://doi .org/10.14277/2385-3034/AnnOc-49-15-20

Diesing, Molly. 1992. Indefinites. Cambridge, MA: MIT Press.

Dobrovie-Sorin, Carmen. This volume. "Negation, des-Indefinites in French and Bare Nouns across Languages."

Farkas, Donka. 2002. "Specificity distinctions." Journal of Semantics 19: 1-31.

Furlan, Erica. 2018. "Indefinite determiners: variation and optionality in an eastern Venetan variety." Term paper, MA in Language Sciences, Ca' Foscari University of Venice.

Gerards, David Paul, and Elisabeth Stark. This volume. "Why "Partitive Articles" Do Not Exist in (Old) Spanish."

Giammarco, Ernesto. 1979. Abruzzo. Pisa: Pacini.

Giusti, Giuliana. 2011. "Structural protocols for linguistic awareness enhancing language identity." Research project at CRASSH. University of Cambridge, October-December 2011. http://www.crassh.cam.ac.uk/people/profile/giuliana-giusti.

Giusti, Giuliana, and Rossella Iovino. 2016. "A protocol for psychverbs." University of Bucharest Working Papers in Linguistics 18, no. 2: 81-97.

Giusti, Giuliana and Iulia Zegrean. 2015. "Syntactic Protocols to enhance inclusive cultural identity. A Case study on Istro-Romanian clausal structure," Quaderni di Linguistica e studi orientali, 1: 117-138

Horn, Laurence. 200o. "Pick a theory, not just any theory." In Negation and Polarity. Syntactic and Semantic Perspectives, edited by Laurence R. Horn and Yasuhiko Kato, 147-192. Oxford: Oxford University Press.

Ihsane, Tabea. 2008. The Layered DP in French. Form and Meaning of French Indefinites. Amsterdam, Philadelphia:John Benjamins.

Ihsane, Tabea. This volume. "Telicity, Specificity, and Complements with a "Partitive Article" in French."

Jaberg Karl, and Jud Jakob. 1928-1940. Sach- und Sprachatlas Italiens und der Südschweiz. Zofingen, Ringier.

Jayez, Jacques, and Lucia M. Tovena. 2002. "Determiners and (un)certainty." In SALT 12 Proceedings, edited by Brendan Jackson, 64-183. Ithaca, NY: Cornell University.

Korzen, Iørn. 1996. L'articolo italiano fra concetto ed entità. Copenhagen: Museum Tusculanum Press.

Krifka, Manfred, Gregory Carlson, Gennaro Chierchia, Godehard Link, Francis. J. Pel- 
letier, and Alice Ter Meulen. 1995. "Genericity: An Introduction.” In The Generic Book, edited by Gregory Carlson and Francis J. Pelletier, 1-124. Chicago: University of Chicago Press.

Kupisch, Tanja, and Christian Koops. 2007. "The Definite Article in Non-Specific Direct Object Noun Phrases. Comparing French and Italian." In Nominal Determination. Typology, Context Constraints and Historical Emergence, edited by Elisabeth Stark, Elisabeth Leiss and Werner Abraham, 189-213. Amsterdam, Philadelphia:John Benjamins.

Laca, Brenda. 199o. "Generic objects: some more pieces of the puzzle." Lingua 81: 25-46. Loporcaro, Michele, and Tania Paciaroni. 2016. "The dialects of central Italy." In The Oxford Guide to the Romance Languages, edited by Adam Ledgeway and Martin Maiden, 228-245. Oxford: Oxford University Press.

Maesano, Debora. 2018. "Expressing indefiniteness in the southern Calabrian dialect of Galati (RC).” Term paper, MA in Language Sciences, Ca' Foscari University of Venice.

Martin, Fabienne, Janayna Carvalho and Artemis Alexiadou. This volume. "Predicates of Personal Taste and Pancake Sentences in Brazilian Portuguese and French."

McNally, Louise. 2020. "Strong and Weak Nominals." In The Wiley Blackwell Companion to Semantics, edited by Daniel Gutzmann, Lisa Matthewson, Cécile Meier, Hotze Rullman, and Thomas Ede Zimmerman (eds.). Oxford: Wiley.

Milsark, Gary. 1977. "Peculiarities of the Existential Construction in English." Linguistic Analysis 3: 1-29.

Molinari, Luca. 2018. "The distribution of indefinite determiners in Piacentino." Term paper, MA in Language Sciences, Ca' Foscari University of Venice.

Perinot, Lara. 2018. "Reduced concord and optionality in Friulian." Term paper, MA in Language Sciences, Ca' Foscari University of Venice.

Picallo, Carme. 1991. "Nominals and nominalizations in Catalan." Probus 3: 279-316.

Picallo, Carme. 1994. "A mark of specificity in indefinite nominals." Catalan Working Papers in Linguistics 4, no. 1: 143-167.

Picallo, Carme. 2012. "The structure of the noun phrase." In The Handbook of Hispanic Linguistics, First Edition, edited by José Ignacio Hualde, Antxon Olarrea and Erin O'Rourke, 263-283. London: Blackwell.

Procentese, Cristina. 2019. "Indefinite determiners in Neapolitan. A comparative study with Italian.” Term paper, MA in Language Sciences, Ca' Foscari University of Venice.

Rohlfs, Gerhard. 1968. Grammatica storica della lingua italiana e dei suoi dialetti; morfologia [Historical grammar of the Italian language and dialects; morphology]. Einaudi: Torino.

Schurr, Hagay. This volume. "Bound To Be? Bare and Partitive-Marked Noun Phrases in Romance Languages and the Emergence of Prominence-Conditioned Patterns."

Schwarz, Bernhard. 2011. "Long distance indefinites and choice functions." Language and Linguistics Compass 5, no. 12: 880-897. 
Stark, Elisabeth. 2008a. "Typological Correlations in Nominal Determination in Romance." In Essays on Nominal Determination. From Morphology to Discourse Management, edited by Henrik Høeg Müller and Alex Klinge, 45-61. Amsterdam, Philadelphia: John Benjamins.

Stark, Elisabeth. 2008b. "The Role of the Plural System in Romance." In The Paradox of Grammatical Change. Perspectives from Romance, edited by Ulrich Detges and Richard Waltereit, 57-84. Amsterdam, Philadelphia: John Benjamins. https:// doi.org/10.1075/cilt.293.04sta.

Stark, Elisabeth. 2016. "Nominal morphology and Semantics-Where's Gender (and 'Partitive Articles') in Gallo-Romance?" In Proceedings of the VII Nereus International Workshop "Clitic Doubling and other issues of the syntax/semantic interface in Romance DPs", edited by Susann Fischer and Mario Navarro, Arbeitspapier 128, 131149. Konstanz: Universität Konstanz Fachbereich Sprachwissenschaft.

Stark, Elisabeth, and David Paul Gerards. This volume. " "Partitive Articles" in Aosta Valley Francoprovençal-Old Questions and New Data."

Strobel, Thomas, and Elvira Glaser. This volume. "The Rise and Fall of Partitive Markers in Some Germanic Varieties."

Tisato, Graziano. 2009. AIs Digital Atlas and Navigation Software http://www3.pd.istc .cnr.it/navigais/.

Tovena, Lucia. 2001. "Between Mass and Count." In WCCFL 20 Proceedings, edited by Karine Megerdoomian and Leora A. Bar-el, 565-578. Somerville MA: Cascadilla Press.

Verkuyl, Henk. 1972. On the Compositional Nature of the Aspects. Dordrecht: Kluwer Verkuyl, Henk. 1993. A theory of aspectuality. Cambridge: Cambridge University Press. Vicenti, Rosa. 2019. "Indefinite determiners in the dialect of Altamura (Central Apulia)." Term paper, MA in Language Sciences, Ca' Foscari University of Venice.

Zamparelli, Roberto. 2008. "Dei ex machina. A Note on Plural/Mass Indefinite Determiners." Studia Linguistica 62, no. 3: 301-327. doi: 10.1111/j.1467-9582.2008.oo149.x. 